\title{
Quando a perda de sentidos no mundo do trabalho implica dor e sofrimento: um estudo de caso sobre fibromialgia
}

| ${ }^{1}$ Rafael da Silva Mattos, ${ }^{2}$ Madel Therezinha Luz |

Resumo: A fibromialgia é uma síndrome reumática que atinge muitas mulheres na população brasileira. Atualmente levanta-se a hipótese de que o regime social de trabalho tem contribuído para o aumento dos índices de fibromialgia, acarretando adoecimento e sofrimento coletivo. $\mathrm{O}$ mal-estar gerado no trabalho somatiza-se na forma de dor crônica, ansiedade e depressão, sintomas típicos da fibromialgia. Este artigo é produto de pesquisa etnográfica realizada com mais de 60 mulheres diagnosticadas com fibromialgia. A perda dos sentidos positivos em relação ao trabalho e o desencantamento com a atividade laboral implicam dor e sofrimento. A fibromialgia vem juntar-se aos casos de LER e DORT como efeito da reestruturação da relação capital-trabalho nas últimas décadas.
1 Professor adjunto do Instituto de Educação Física e Desportos da UERJ. Pesquisador do Grupo de Pesquisa CNPq Racionalidades Médicas e Práticas de Saúde. Endereço eletrônico: profmattos2010@ gmail.com

2 Professora titular aposentada do Instituto de Medicina Social da UERJ e professora colaboradora da Universidade Federal do Rio Grande do Sul e da Universidade Federal Fluminense. Endereço eletrônico: madelluz@uol.com.br 
A fibromialgia é uma síndrome reumática caracterizada principalmente por dor músculo-esquelética crônica e por 18 locais corporais dolorosos específicos à palpação (tender points). Chega a atingir cerca de $2 \%$ da população brasileira e corresponde a $20 \%$ do ambulatório de reumatologia. É frequentemente associada a fadiga generalizada, distúrbios do sono, dores de cabeça, rigidez matinal, dispneia, dificuldade de memorização e concentração, ansiedade, alteraçôes no humor e depressão. As dores corporais são frequentes no pescoço, costas, ombros, cintura pélvica, mãos, mas qualquer local do corpo pode ser afetado (CATHEBRAS et al., 1998; SANTOS et al., 2006).

Segundo Sá et al. (2005), as primeiras descrições de sintomas datam de meados do século XIX. Contudo, somente em 1977 o reumatologista Hugh Smythe e o psicólogo Harvey Moldovsky detalharam o quadro clínico e propuseram os primeiros diagnósticos "objetivos". A média de idade dos pacientes tem variado entre 30 e 60 anos, sendo maior a incidência no gênero feminino (90\%).

Em nossa pesquisa, realizada no projeto de extensão "Tratamento Interdisciplinar para Pacientes Portadores de Fibromialgia", ${ }^{1}$ no Instituto de Educação Física e Desportos da Universidade do Estado do Rio de Janeiro (UERJ), havia 65 participantes e apenas um homem. O projeto foi criado em 2000 e desde então foram atendidas gratuitamente mais de 300 mulheres e apenas dois homens. As mulheres são predominantemente casadas (60\%), com educação básica completa (42\%) e ensino superior (23\%), moradoras da Zona Norte do Rio de Janeiro (60\%).

Um dos primeiros médicos a tentar definir o conjunto de sinais e sintomas que é hoje conhecido como fibromialgia foi Frederick Wolfe, diretor do Centro de Pesquisa sobre Artrite, em Wichita, Kansas, interessado nessa condição clínica na década de 1970. Tal como muitos outros reumatologistas, ele estava percebendo um número crescente de pacientes que se queixavam de dor muscular difusa, mas que, após o exame físico, não mostravam nenhuma evidência de lesão ou inflamação. Testes laboratoriais, raios-X, biópsias e tecidos musculares não demonstravam qualquer indício da patologia. A inexistência de marcadores sanguíneos dificultava o diagnóstico e, por conseguinte, a terapêutica. Somente em 1990, entretanto, o termo "fibromialgia" formalmente recebeu uma nomenclatura médica, designando uma condição de persistência 
da dor muscular em todo o corpo, acompanhada de fadiga acentuada, insônia e depressão (GROOPMAN, 2000).

Devido ao grande número de pessoas afetadas, seu caráter debilitante, quando não incapacitante, a fibromialgia tornou-se um assunto de interesse internacional. É apresentada com maior regularidade na mídia (jornais e televisão), e é o foco de centenas de sites da internet. Em revisão da literatura sobre a prevalência de fibromialgia na população mundial a partir dos critérios propostos pelo American College of Rheumatology, Cavalcante et al. (2006) encontraram dados apontando uma prevalência entre $0,66 \%$ e $4,4 \%$, sendo mais prevalente em mulheres do que em homens, especialmente na faixa etária entre 36 e 60 anos. Os estudos com crianças, adolescentes e grupos especiais são escassos e pouco conclusivos. A prevalência de dor crônica difusa na população é superior à prevalência de fibromialgia, sendo encontrados valores entre 11 e 13\%. No Brasil, os dados da Sociedade Brasileira de Reumatologia (2004) apontam a prevalência de aproximadamente de $2 \%$ na população e o motivo por aproximadamente $15 \%$ a $20 \%$ das consultas em ambulatórios de reumatologia.

Para El-Hage et al. (2006), a dor crônica "inexplicada" pode ser uma manifestação somática de um sofrimento psíquico negligenciado. O fato de muitos pacientes não apresentarem alterações fisiológicas objetivas reforça a crença de que a fibromialgia é uma psicopatologia. Os pacientes de fibromialgia muitas vezes são considerados pacientes psiquiátricos, principalmente porque as especialidades biomédicas não conseguem um consenso diagnóstico. É comum que os médicos encaminhem os pacientes para ambulatórios de psiquiatria e que o diagnóstico seja “depressão". A racionalidade médica científica ocidental (biomedicina) reconhece a legitimidade de patologias a partir dos exames biomédicos, crescentemente por imagens. Quando os exames não conseguem "ver" a doença, o quadro clínico torna-se incerto e o sujeito é enviado ao psiquiatra. A fibromialgia não consta como síndrome ou patologia no Manual Diagnóstico de Doenças Mentais (DSMIV) utilizado como referência internacional (APA, 1994). Logo, oficialmente não é considerada como um transtorno mental e comportamental.

A depressão é sempre uma questão importante a ser considerada, em função de sua proximidade com a fibromialgia, embora ainda não seja possível estabelecer uma relação causal. Sordet-Guepet (2004) afirma que as classificações biomédicas, muitas vezes, consideram a fibromialgia como 
um mal-estar subjetivo. Face à padronização biomédica ou às classificações oficiais, a fibromialgia não pode ser detalhada em sua etiologia e mecanismos fisiopatológicos, estando limitada a um mal-estar multiforme subjetivo. Por sua característica invisível, a fibromialgia permanece inexplicada, porém sempre caracterizada pela dor crônica e associada à depressão.

Estudos biomédicos procuram explicar a relação entre depressão e fibromialgia, mais ainda carecem de resultados significativos. Cerca de 30\% a 50\% dos pacientes têm depressão. Ansiedade, alteração do humor e do comportamento, irritabilidade ou outros distúrbios psicológicos acompanham cerca de um terço destes pacientes (SBR, 2004). Sordet-Guepet (2004) afirma, entretanto, que a fibromialgia não é reconhecida como doença psicológica, permanecendo negada pelos psiquiatras, a despeito de uma coabitação estreita com um componente psicossomático. Ao final da consulta, o paciente sai insatisfeito porque tem uma incapacidade durável, mas pouco visível. E porta dores não explicadas no sentido de uma "doença". Há uma incapacidade física, porém pouco visível, o que torna a compreensão e o diagnóstico difíceis. As dores caracterizam uma condição de doença, mas uma doença que é dificilmente explicada pela biomedicina (FOUCAULT, 2003; LUZ, 2004).

Herzlich e Pierret (1991) afirmam que a doença estabelece a legitimidade da medicina. O médico, depositário de um saber e de conhecimentos técnicos, identifica o mal utilizando os meios necessários ao diagnóstico. A prescrição da terapêutica é a resposta obrigatória para a doença: deve-se se cuidar quando se está doente e a cura esperada é uma verdadeira arte, pois cada médico tem o dever de curar. Convicta de sua legitimação, fundada sobre a ciência e a técnica, a medicina estendeu progressivamente sua jurisdição a outros campos além daquele da doença. Ela tende, cada vez mais, a prescrever uma higiene da vida, ditar a adoção de comportamentos sadios e racionais em vista de conservar a saúde. Mas como lidar com um tipo de adoecimento no qual o médico se encontra diante de uma crise ético-social e epistemológica? Como um doente pode se apresentar para um médico dizendo que sente dores se os exames indicam normalidade?

Sá et al. (2005) constatam que entre o aparecimento dos sintomas (dor) e o diagnóstico a demora é de cinco a oito anos. Durante anos, os pacientes fibromiálgicos são rotulados como doentes psiquiátricos, uma vez que, apesar das queixas generalizadas de dor e da acentuada fadiga, estas não são justificadas 
pelas análises biocientíficas nem fundamentadas por outros exames médicos realizados. Essa categorização como pacientes psiquiátricos é muito mais decorrente da incapacidade da biomedicina em lidar com um mal-estar subjetivo do que uma precisão diagnóstica.

Segundo Rosenberg (2006), o psiquiatra, por muito tempo, foi considerado administrador de dilemas sociais e emocionais. Desde sua origem como especialidade médica no século XIX, a psiquiatria foi um definidor de limites, do normal e do anormal. Ao mesmo tempo, a psiquiatria tem sido o residuário da contestação oscilante do limite entre doença e desvio. A legitimidade de muitas categorias de supostas doenças mentais ainda é contestada, o que evidencia a natureza problemática das categorias diagnósticas psiquiátricas. A não-existência de marcadores biológicos permite que as pessoas falem, questionem e até produzam identidades baseadas em categorias psiquiátricas

Não são encontradas provas diagnósticas laboratoriais, causas etiológicas e fisiológicas explicativas. Essa carência de exames quase autoexplicativos ou de dados sobre as causas orgânicas da fibromialgia coloca-se como um grande problema para a biomedicina. No ambiente familiar ou profissional, as pacientes são rotuladas como "Maria das Dores". No tratamento interdisciplinar para pacientes portadores de fibromialgia da UERJ constatamos, através de um levantamento com todas as mulheres, que o tempo entre o início dos sintomas e o diagnóstico de fibromialgia dura cerca de oito anos. Tal demora não pode ser explicada somente pelo aparecimento gradativo dos sintomas, mas principalmente pela dificuldade existente entre as distintivas especialidades médicas de entrar em consenso sobre um quadro clínico caracterizado por ausência de marcadores bioquímicos e radiológicos de doença. A biomedicina entra em conflito diante da fibromialgia porque o sintoma subjetivo da dor é insuficiente - no saber biomédico - para o diagnóstico de fibromialgia. Berber et al. (2005) concluíram, em pesquisas brasileiras, que $40 \%$ dos pacientes de fibromialgia estudados sofriam de dor corporal há mais de dez anos, apesar de 48,6\% receberem o diagnóstico de fibromialgia há menos de dois anos.

O paradigma da biomedicina (TESSER, 2007) se fundamenta na supervalorização da pesquisa científica biomédica como a voz da verdade. Só os testes, padronizações, estatísticas (MOULIN, 2008) e protocolos biomédicos podem afirmar se algo é verdadeiro, se é saber, se é conhecimento, se é válido. 
São os instrumentos produtores de verdade. A verdade da cura virou cura da doença cientificamente definida. Isso é exigido pela legitimação metodológica científica e sua expressão estatística. Os ensaios clínicos controlados (remédio $\mathrm{x}$ placebo; remédio $\mathrm{x}$ remédio) tornaram-se os instrumentos produtores de verdade. A validação e estabelecimento das verdades vão migrando do cotidiano dos tratamentos e evoluções dos doentes para o âmbito dos estudos científicos de validação das intervenções, tipicamente os ensaios clínicos controlados e os estudos de coortes.

O orgulho em termos de conhecimento terapêutico passa a ser saber os últimos resultados das meta-análises e dos grandes estudos caso-controle sobre a fibromialgia e respectivos medicamentos. A construção social das verdades diagnósticas (monopolizadas pela biomedicina e pela indústria científica dos exames complementares e de imagem) e terapêuticas (monopolizadas pelos ensaios clínicos controlados e pelas indústrias farmacêuticas) desdobrou-se em processo de desresponsabilização social pela missão terapêutica por parte dos (bio)médicos. Mas como diagnosticar a fibromialgia diante dessa constatação? A biomedicina procura constantemente a "neutralidade científica", retirando a influência da cultura nos processos de dor, ao tentar explicar seus mecanismos exclusivamente pelas neurociências. Imagens cerebrais fornecem argumentos dentro da lógica hegemônica biomédica para a "verdadeira explicação" da dor a partir de disfunções supraespinhais dos centros de regulação da dor.

Luz (2005a) constata, em estudos sobre clientela do sistema público de saúde, que a terapêutica da biomedicina é incapaz de atender às demandas de cuidado dos pacientes. O saber terapêutico centra-se no combate e controle das doenças diagnosticáveis, desviando-se do paciente e sua vida, tornando-se progressivamente um processo de racionalização da ação biomédica sobre o corpo doente. Estes passam a ser vistos cada vez mais como unidades homogêneas.

Para Tesser e Luz (2008), a biomedicina apresenta um caráter analítico, embasada no imaginário mecânico da física clássica, e uma doutrina implícita que "vê" a doença que se expressa por sinais e sintomas objetiváveis. Reiteramos: como tratar uma mulher com fibromialgia que tem como principal sintoma a dor crônica que não pode ser objetivada em lesão anátomo-patológica? Face a este vazio deixado pela biomedicina, as ciências humanas e sociais vêm sendo solicitadas a cooperar nos estudos sobre a saúde. 
Marques et al. (2001) procuraram avaliar e comparar a intensidade da dor referida por pacientes com pacientes de fibromialgia, osteoartrite ou lombalgia, visando propor o tratamento fisioterapêutico mais adequado para estes grupos de pacientes. Constatou-se que cada uma dessas três patologias apresenta uma experiência singular da dor, sendo que os pacientes com fibromialgia relatavam dores mais intensas, utilizando expressōes do tipo: "maldita", "miserável", "exaustiva", "enlouquecedora".

\section{A construção sociocultural da dor}

Peito, coxas, lábios, barriga, umbigo, mamilos, pênis, testículos, etc., partes do corpo: mas também algo mais. Nossos corpos e as partes deles são carregados com simbolismo cultural. Peso e estatura, comida e bebida, sexualidade, gestos e linguagens corporais, até mesmo as doenças não são simplesmente fenômenos físicos: eles são fenômenos sociais. $\mathrm{O}$ corpo não é somente um conjunto de pele e ossos. O corpo é primariamente o self. Ao carregar significados, o corpo torna-se o principal constituinte da identidade pessoal e social (DURET; ROUSSEL, 2003).

Resnik e Rehm (2001) constatam que a dor é subtratada pelos médicos porque ela não se insere na abordagem científica e biomédica da saúde e doença na formação médica. A dor é subjetiva, não favorecendo a compreensão objetiva por parte dos médicos. A causa da dor e seu mecanismo orgânico são ainda malcompreendidos, além de a dor ser considerada como um "mero" sintoma, não uma doença. Sendo assim, a dor não se encaixa no modelo de conhecimentos biomédicos especializados.

O fato de a dor ser uma resposta biológica universal e individual aos estímulos sensitivos não impede que sua percepção e os comportamentos que ela provoca quer eles sejam verbais ou não-verbais, têm relação com a cultura. São os grupos sociais que vão conceder à dor um status de normalidade ou de fatalidade, ou ainda valorizá-la. É o caso de alguns rituais sociais, como os rituais de passagens dos meninos à idade adulta, ou os rituais de autotortura que visam adquirir prestígio social.

A dor é compreendida como uma experiência sensorial e emocional desagradável, associada ao dano presente ou potência em termos de lesão. Essa é a definição mais comum de dor, descrita inclusive pela International Association for the Study of Pain (IASP). Ela foi lançada oficialmente em 9 de maio de 
1974 e seu periódico oficial, Pain, foi publicado em 1975. A pergunta elaborada durante muitos anos e dificilmente respondida é: a dor é orgânica ou psicogênica? Atualmente, procuramos responder essa pergunta de outra forma: a dor é uma experiência biológica, psíquica e social. É, portanto, biopsicossocial.

A dor ultrapassa a esfera biomédica, pois é uma manifestação da relação entre o indivíduo e a sociedade. As formas de sentir e de expressar a dor são regidas por códigos culturais, e a própria dor se constitui a partir dos significados conferidos e compartilhados pela coletividade, que sanciona as formas de manifestação dos sentimentos. A dor, portanto, se insere num universo de referências simbólicas, configurando um fato cultural. Na dor se revelam não somente a singularidade do sujeito, mas também as particularidades da cultura (LE BREATON, 1995).

Vamos retomar a discussão elaborada por Durkheim (2004) sobre o fato social, para ressaltar a característica social das formas de sentir e expressar a dor. Durkheim irá conceituar o fato social como toda maneira de agir, fixa ou não, suscetível de exercer sobre o indivíduo uma coerção exterior; que seja generalizada na extensão de uma sociedade, que apresente existência própria, independentemente das manifestações individuais. Com a sociologia francesa de Durkheim, estabelece-se o argumento de que a sociedade já está pronta e cabe ao indivíduo se inserir nela.

Contudo, a grande contribuição que Durkheim coloca para nosso estudo sobre a fibromialgia é a constatação sociológica de que a maneira de ser (e de se comportar) também é social. Durkheim chega a afirmar que os fatos sociais podem ser de ordem anatômica ou morfológica. No mesmo sentido, os sentimentos são transmitidos socialmente pela educação dos sujeitos. Diante disso, retomamos um dos argumentos principais desta pesquisa, que é a constatação empírica e analítica de que a forma de expressar, sentir e discursar sobre a dor corporal é produzida e construída socialmente, perpassando e até mesmo ultrapassando as consciências individuais, como diria Durkheim. Podemos, da mesma forma, retomar o clássico estudo de Marcel Mauss (2005) intitulado A expressão obrigatória dos sentimentos, quando o autor afirma que sentimentos, expressões orais, choros e lamentos não são apenas psicológicos, tampouco fisiológicos, mas fenômenos sociais.

A reclamação dador, ademanda poracolhimento no tratamento multidisciplinar para pacientes portadores de fibromialgia da UERJ e a busca recorrente por 
licenças médicas do trabalho não são apenas características da "patologia", mas compõem um conjunto de signos e sinais coletivos eminentemente produzidos pela cultura. Haveria, portanto, uma gramática das emoções e sentimentos que é fruto da internalização das estruturas sociais. Isso não quer dizer que a emoção do sujeito não seja genuína, mas aos olhos do cientista social a experiência da lágrima, do choro, da dor e do sofrer possuem uma etiologia sociocultural.

É como a dádiva, tratada por Mauss (1974) em Ensaio sobre a dádiva, percebida como singular, voluntária e consciente pelo nativo, mas ao olhar sociológico mostra-se uma "obrigação" social de dar, receber e retribuir. Em nosso estudo com enfoque na dor corporal, a fisiologia, a fisiopatologia, a sociologia, a antropologia se misturam formando uma amálgama de informações disponíveis ao cientista social. Mauss ressalta diversas vezes que a natureza psíquica e a natureza moral do indivíduo se manifestam no corpo. É na materialidade da existência corporal que as dores da sociedade se manifestam.

Dos pacientes avaliados por um reumatologista, 98\% apresentam a dor independentemente do diagnóstico de fibromialgia - como queixa principal. O mal-estar gerado pela dor e seu impacto na qualidade de vida, com prejuízos para atividades cotidianas e profissionais, levam muitas mulheres a procurarem $o$ reumatogista. Entretanto, o diagnóstico torna-se difícil, pois não existem exames laboratoriais para mensurar a dor.

Vale ressaltar que a escolha do tratamento, o conhecimento sobre este e a crença em sua eficácia possuem relação com o universo sociocultural, no qual mulheres estão inseridas. A dor toca sensivelmente na dimensão simbólica da cultura, pois as crenças e valores partilhados entre médicos e pacientes constituem atividades e práticas - discursivas ou não - socialmente organizadas. Nesse sentido, esta pesquisa não se interessou em elaborar apenas uma análise macrossociológica, tampouco recorrer a um modelo explicativo, mas realizar uma compreensão sócio-antropológica interpretativa voltada para os comportamentos/condutas e discursos específicos de mulheres portadoras de fibromialgia na sua interface com o regime produtivo de trabalho e o adoecimento.

Para Le Breton (1995), a dor não é somente um "fato fisiológico", mas principalmente um "fato da existência". Não é somente o corpo que sofre, mas um ser humano que pertence a uma cultura e a uma sociedade, com uma subjetividade singular e uma história própria. A anatomia e a fisiologia 
não são suficientes para explicar essas variações sociais, culturais, pessoais e mesmo contextuais. A relação íntima com a dor depende da significação que a dor possui no momento em que atinge o indivíduo. Entretanto, não podemos fugir do reducionismo biológico deslocando-nos para um reducionismo cultural; é preciso reconhecer, sem dúvida, que a dor é uma manifestação de defesa do organismo. Privada da capacidade de sentir a dor, a existência humana tornase terrivelmente vulnerável. A dor é um aviso para todo perigo que ameaça nossa integridade física. Algumas pessoas nascidas sem a capacidade de sentir dor relatam problemas cotidianos sérios. Gravemente feridas, elas não percebem nada. Elas mordem a boca ou a língua sem perceber. Furam a bochecha com um lápis ou quebram seus próprios dentes sem se dar conta disto. Elas se queimam, se machucam, fraturam membros.

A falta de sensibilidade congênita à dor, por exemplo, é uma enfermidade que expõe o indivíduo a todos os perigos reais existentes no meio: de um dedo esmagado em uma porta até a absorção de um líquido fervendo, assim como uma queda com fraturas. A incapacidade de sentir dor impede o indivíduo de adotar defesas que preservam o próprio organismo. Le Breton utiliza como exemplo a hanseníase, doença a qual um dos sintomas é a insensibilidade à dor. Incapazes de sentir o sinal doloroso marcando a alteração dos tecidos corporais, os doentes se machucam cruelmente sem perceber. Eles forçam seu corpo a limites que não percebem. Em alguns países, os ratos comem as carnes dos leprosos sem quem eles acordem ou possam se defender.

\section{Trabalho e dor}

A palavra trabalho é originária do vocábulo latino tripaliare e do substantivo tripalium, aparelho de tortura para amarrar os condenados ou os animais difíceis de ferrar. Daí se origina a associação do trabalho com tortura, sofrimento, labuta. $\mathrm{Na}$ economia política moderna clássica, o trabalho foi considerado a fonte de riquezas e o fundamento do direito à propriedade privada. Após a Reforma Protestante, uma vida consagrada ao trabalho, à produção de riquezas e ao reinvestimento na máquina produtiva se tornou um meio de viver a fé. A ascese através do trabalho vincula-se a um ethos que impulsionara o capital (WEBER, 2004).

Nesse sentido, a categoria "trabalho" é tão histórica tanto quanto é o homem. Marx $(2004,2008)$ afirma que, pelo trabalho, o homem transforma a natureza 
e transforma a si próprio. Os seres humanos não nascem sujeitos, tornam-se sujeitos através do processo social do trabalho. A mediação entre o homem (ser da natureza) e o sujeito (ser da cultura) se faz pelo trabalho. Aqui, o trabalho coloca-se como categoria central na vida humana: a mediação essencial para a "humanidade do homem”. Para Marx, a história da humanidade é a produção do homem pelo trabalho humano, considerado uma atividade social, que implica necessariamente um laço social de cooperação, de socialização e organização coletiva. Sem o trabalho não haveria, portanto, sociedade e, consequentemente, existência. No trabalho, o homem se reconhece e se constitui como tal, como ser social, consciente, criativo e reflexivo; diferente do animal que é instinto, atividade. Não é à toa que Robert Castel (1995) afirma que o trabalho é um suporte privilegiado de inscrição na estrutura social.

Se o corpo é um instrumento mediador entre o homem e a sociedade, cabe-nos ressaltar que ele é o primeiro substrato a sofrer com a intensificação do regime produtivo de trabalho. Queremos ressaltar neste texto que o regime social de trabalho, com seu ritmo, estresse, produtividade e a competitividade contribuem para o maior adoecimento e sofrimento das mulheres. Esse mal-estar gerado se manifesta corporalmente na forma de dor e contribui para o aumento do número de diagnósticos de fibromialgia. A impossibilidade de responder à demanda do tipo ideal de "trabalhador produtivo" no regime de trabalho atual gera esse sintoma manifestado corporalmente na forma de dor.

Dejours (2008), na conclusão de seu livro, afirma que questão é saber que tipo de homens a sociedade fabrica através da organização do trabalho. Poderíamos, então, fazer a seguinte pergunta: que tipo de doenças a sociedade fabrica através da organização e do regime de trabalho? Fibromialgia? LER? DORT? Depressão? Fobia? Síndrome do pânico?

Ao entrevistarmos mulheres com fibromialgia, foi de nosso interesse saber se elas, em algum momento, precisaram obter licença médica do trabalho em virtude das dores, se estavam de licença, assim como levantamos uma série de informaçôes sobre o trabalho, o ritmo, o estresse, entre outros. Abaixo, alguns relatos dessas mulheres:

Em 2001 trabalhava em telemarketing em torno de dez horas por dia e tive uma crise muito grande de depressão. Além das metas, éramos gentilmente solicitados a fazer horas extras diariamente. Creio que o meu trabalho contribui muito para a fibromialgia, pois diversos atendentes tiveram outros tipos de doenças e tiveram que entrar de 
licença tipo: crises de tendinite, crises de estresse, síndrome do pânico, depressão, um rapaz de 23 anos chegou a ter um ataque cardíaco dentro da central de atendimento. Atualmente me encontro de licença por conta da fibromialgia (45 anos, solteira, atendente de call center).

O que desencadeou minha doença foram crises de sistema nervoso por causa do trabalho. Eu sou professora de matemática e lecionava todos os três turnos com turmas de 60 alunos. Era terrivelmente estressante devido ao número de alunos na sala. No trabalho não podia faltar nunca. Era trabalho escravo mesmo. Meu trabalho contribuiu para a doença, sim. Contribuiu muito e me arrependo de ter escolhido essa profissão (44 anos, solteira, professora).

Já tive que ficar de licença várias vezes. Faltei muito por causa disso, pois as crises sempre vinham muito próximas dos meus plantôes. Atualmente estou há cinco meses de licença médica. Quando estou de licença médica minhas crises diminuem em $90 \%$. Eu acho que meu trabalho contribuiu para a doença, sim. Era estressante fisicamente, psicologicamente e emocionalmente. A própria natureza do trabalho faz a gente adoecer. A fibromialgia desencadeou de vez lá. Eu já tive depressão. Mais, além disso, trabalho três anos em presídios, quer dizer, a cada cinco dias eu fico 24 horas sob tensão. A gente fica mais tenso no trabalho e isso pode causar mais dores. Algumas vezes ficava irritada pela incompreensão das pessoas e não tinha o mesmo rendimento no trabalho. Já tive problemas de relação de trabalho por isso (27 anos, solteira, agente penitenciária).

Sim. Fiquei mais ou menos 18 meses de licença pelo INSS por causa das dores. Eu acho que meu trabalho contribuiu em $90 \%$ para a doença. Era muito estressante, tenso. Eu era bancária. Fazia de tudo: caixa, atendimento direto ao público, gerenciamento e outros. Era tudo muito estressante e as cobranças eram impossíveis, pesadas, era tudo ou nada (30 anos, casada, bancária).

Podemos perceber que relatam a sobrecarga de trabalho e o ambiente laboral como fatores intimamente relacionados. Em alguns momentos, podemos perceber que essas mulheres evocam o ambiente de trabalho como causador ou desencadeador do adoecimento. Não corroboramos essa relação causal, mas compreendemos que existe íntima conexão entre o regime social de trabalho contemporâneo e o adoecimento.

Múltiplos fatores de risco estão entrelaçados para compreendermos os distúrbios músculo-esqueléticos. Fatores biomecânicos, como a repetição dos gestos, a força exercida, a amplitude dos gestos, a manutenção prolongada da uma postura estática e exposição ao frio estão relacionados como fatores de risco. Fatores organizacionais relacionados ao regime social de trabalho, como a restrição de tempo para realizar atividades, monotonia, ausência de capacidade de auto-organização, ausência de tempo de recuperação também compõem os 
fatores de risco, assim como os fatores psicossociais (estresse, falta de apoio da

hierarquia no ambiente de trabalho, fragilidade da coletividade do trabalho).

$\mathrm{O}$ peso dos fatores psicossociais ligados ao trabalho (principalmente do estresse profissional) na aparição dos distúrbios músculo-esqueléticos é sem dúvida real (DURAND, 1978; ROQUELAURE, 2008).

Já precisei obter licença médica do trabalho em virtude das dores no meu corpo várias vezes. Eu era química industrial e fazia controle de qualidade de produtos químicos. Às vezes era muito estressante. Eu acho que meu trabalho contribuiu, sim, para minha doença. Havia cobranças diversas, tais como urgências, prazos, pressão de fornecedores etc. Acho que contribuiu, sim e muito. Na verdade acredito que foram várias coisas. Acredito que muitas mudanças: insatisfação profissional, trabalho árduo, muita responsabilidade, pressão, cobranças (54 anos, solteira, administradora de recursos humanos).

Eu acho que o que desencadeou a fibromialgia foram vários fatores. Trabalho com grande nível de estresse, má alimentação, fatores emocionais e excesso de responsabilidades. Acredito também que toda a minha vida foi um caminho direto para a fibromialgia. [...] As cobranças no trabalho eram intermináveis. Começava com a Corregedoria-Geral, depois os juízes, advogados e partes, bem como os colegas, devido a exercer função com gratificação. Tenho certeza que meu trabalho contribuiu para a fibromialgia (46 anos, casada, funcionária pública).

Eu estava insatisfeita com a forma que eles conduziam as coisas, a competitividade e a remuneração, pois era muita exploração por tão pouco salário, além do sacrifício por anos de estudo e dedicação. Meu trabalho era de contrato, portanto tive que pedir para sair por causa da pressão e porque já não suportava mais trabalhar por conta das dores (33 anos, divorciada, fisioterapeuta).

Bom meu trabalho é bastante estressante, e isso faz com que eu sinta dores. Estou trabalhando na mesma empresa há mais de três anos, eu procuro não demonstrar as minhas dores, no entanto, muito sabem o que tenho. Quando estou me sentindo muito mal vou à enfermaria da empresa e tomo um medicamento pra aliviar os sintomas, meu trabalho de certa forma contribui, sim, por conta do nível de estresse (27 anos, solteira, engenheira).

Quando os colegas de trabalho não acreditam em sua dor, quando a chefia prioriza a produção/produtividade e não a saúde do trabalhador, a mulher com fibromialgia sente-se empurrada para manter o ritmo de trabalho elevado, pois como não tem lesão anátomo-patológica visível, não tem como provar o sofrimento, tampouco o adoecimento. Cria-se uma situação constrangedora e desconfortável na qual a mulher precisa manter seu posto de trabalho, mas ao mesmo tempo as dores musculares se intensificam. Abaixo há o relato de uma mulher que nos conta como seu trabalho, antes uma atividade valorosa e satisfatória, foi se tornando 
produtora de adoecimento e sofrimento. Mesmo atingindo 200\% da meta estabelecida por uma empresa privada, o reconhecimento não foi proporcional ao esforço de trabalho. Daí seguiram-se episódios de depressão, melancolia e tentativas de suicídio. $\mathrm{O}$ único refúgio, não satisfatório, era a cama, onde ela chorava o dia inteiro. Não é surpreendente que a entrevistada relate o desejo de morrer, que foi impulsionado pela perda de sentidos na atividade profissional.

Quatro meses depois da minha promoção, conseguimos atingir 200\% da meta, fomos além do esperado e consequentemente ganhei um prêmio. Eu esperava ser promovida para o próximo cargo. Foi aí que comecei a desmoronar e pensar que meu tempo no banco estava acabado, então corri atrás do tempo, meu físico já não aguentava mais aquela vida de andar o dia todo na rua de salto e pastas pesadas na mão. Houve uma mudança na gerência da minha agência. Simplesmente depois de ela ter chegado, fui tão humilhada por ela que entrei em depressão profunda, aquilo para mim foi a gota d'água, era o que faltava para eu me acabar. A partir daquele episódio, entrei de licença médica e consequentemente pelo INSS. Durante a minha licença, ela se estressou comigo por telefone algumas vezes que também foi o fim para mim, até que tentei suicídio duas vezes por conta do trabalho eu não achava mais apenas viver, não conseguia levantar da cama, chorava o dia todo só pensando em morrer (30 anos, casada, bancária).

O sofrimento psíquico de muitos trabalhadores, derivado do controle, pressão, intensidade do trabalho, medo de demissão, relações tensas e competitivas entre seus pares é desconsiderado ou desprezado pelos empregadores. Na melhor das hipóteses, a preocupação com as LER ou DORT estão presentes, mas não com o regime social do trabalho que provoca mal-estar psíquico e subjetivo.

Quando a relação homem-trabalho é bloqueada, fraturada, desintegrada, o adoecimento se manifesta de forma não apenas individual, mas coletiva. Para Kokoreff e Rodriguez (2005), o trabalho perdeu seu grande papel de integrador e sua capacidade de dar sentido às identidades coletivas. Surgem, doravante, doenças mentais ou somáticas. De uma hipertensão arterial sistêmica à fibromialgia, o sofrimento varia com o tipo de organização do trabalho que cria insatisfação, cujas consequências não se limitam a um desgosto particular.

$\mathrm{O}$ que constatamos nesta pesquisa até o momento é que o regime social de trabalho pode ser um dos fatores que contribuem para a manifestação do sofrimento na forma de dor, mas não se constitui como causalidade ou etiologia predominante. Há sim, uma relação de sofrimento entre o viver cotidiano e o trabalho. Muitas mulheres gostariam de trabalhar, mas em virtude da dor, não possuem condições, enquanto outras não gostariam de retornar à mesma atividade profissional. 
A situação limite é criada, sobretudo, quando a doença coloca em risco

a autonomia física ou psíquica do indivíduo. Essa situação provoca um deslocamento na relação do paciente com aqueles ao seu dor nas diferentes formas de interação. A chegada de uma doença grave, como a fibromialgia, exige muitos cuidados específicos. Essa situação demanda a participação efetiva, acolhimento e atenção de todos que vivem em torno do doente, inclusive colegas de trabalho (AIACH et al., 1989).

Desriaux (2008) afirma que os distúrbios músculos-esqueléticos estão em primeiro lugar entre as doenças profissionais reconhecidas. Eles são fontes de incapacidades severas que comprometem a saúde, o emprego e a vida das pessoas atingidas. Para eliminar esses distúrbios e doenças, entre elas a fibromialgia, ações de prevenção pontual são insuficientes, mas exige-se uma vontade forte e constante das empresas e empregadores. Se essas patologias não são mortais como uma exposição ao câncer, elas são fontes de incapacidades severas que comprometem a saúde, o emprego e a vida social das pessoas atingidas. Além dos fatores "clássicos", como hipersolicitação muscular e articular, restrição do tempo para realização de tarefas laborais e aumento da intensidade do trabalho, outros já são identificados: estresse e aumento exagerado das exigências combinadas de velocidade e precisão.

Sabe-se igualmente que alguns modelos organizacionais constituem verdadeiros lócus produtores de doenças laborais músculo-esqueléticas. O sistema just in time modificou a organização do trabalho, demandando às empresas a se adaptar eliminando mão de obra para aumentar a produtividade e desenvolver estratégias de antecipação dos imprevistos. A utilização de ginástica laboral ou a correção dos gestos e posturas não são tão eficazes como se imagina. Ficou evidente, ao longo de nossa pesquisa, que apontar o regime social de trabalho como causa da fibromialgia ou as licenças médicas como efeito da fibromialgia são hipóteses interpretativas plausíveis, mesmo em razão de outros possíveis fatores que contribuem para o adoecimento.

Um achado valioso de nossa pesquisa é a relação entre o regime social de trabalho e a docência. Há uma especificidade dessa atividade profissional que merece atenção em futuros. Nossos dados revelam, de forma indireta, a precarização da docência. Inúmeras mulheres com fibromialgia são professoras e relatam o difícil cotidiano profissional marcado por dor simbólica (humilhações, 
desrespeito, baixa remuneração) que se transforma em dor corporal. Vejamos abaixo relatos de mulheres com fibromialgia que são (outras não mais) professoras:

Sou professora de português e literatura e pós-graduada em linguística. Atualmente não estou trabalhando porque estou de licença médica. Estou encostada no INSS. Acredito sim que o que desencadeou minha fibromialgia foi o emprego, pois era muito estressante, com isso passei a ter insônia e falta de atividade física. Acredito que fiquei doente por causa do meu trabalho. Eu dava aula de redação para oito turmas. Trabalhava em uma comunidade carente e muitos dos alunos eram problemáticos. Eu faltava muito devido à dor e as pessoas não compreendem muito bem os fibromiálgi$\cos$ (24 anos, solteira, professora).

Eu acho que meu trabalho contribuiu para a doença, sim. Estou de licença médica até hoje, apesar dos médicos dificultarem minha licença por não acreditarem na fibromialgia. $\mathrm{Na}$ verdade acho que o meu trabalho desencadeou a fibromialgia. Eu sou professora e no período que eu estava com esse início de sintoma foi um período muito estressante mesmo (28 anos, casada, professora).

Em muitos períodos durante o ano, preciso tirar licenças médicas em função da fibromialgia, o que é muito complicado. Além de nem sempre conseguir licenças médicas e faltar assim mesmo, também tenho que lidar com companheiros de trabalho que acreditam que sou uma má profissional em virtude das faltas ou do estado em que vou trabalhar quando estou em crise (35 anos, casada, professora).

Eu era professora de ensino fundamental e estava detestando o exercício da profissão. Fiquei um bom tempo nessa luta de trabalhar com algo que não suportava. Com certeza isso contribuiu em muito pra ficar como fiquei (solteira, 55 anos, professora).

Em todos esses relatos, sem exceção, encontramos o ambiente de trabalho, a tensão no trabalho e o regime precarizado e degradante intimamente relacionado com o adoecimento. Todas relatam como essa atividade profissional, em certas condições, contribuiu para o adoecimento.

Oliveira (2004) ressalta que, diante da reestruturação produtiva que ocorreu nas últimas décadas no Brasil, novas demandas têm sido apresentadas à educação escolar com relação a seus objetivos, refletindo mudanças nas formas de gestão e organização do trabalho na escola. As mudanças trazidas pelas reformas educacionais teriam resultado em intensificação do trabalho docente, aplicando o desgaste e a insatisfação por parte destes. Para a autora, a precarização do trabalho docente está intimamente ligada aos processos políticos e econômicos originados na década de 1970. Enquanto nos anos 1960 se assistiu, no Brasil, à tentativa de adequação da educação às exigências do ideário nacional-desenvolvimentista, os anos 1990 demarcaram uma nova realidade: o imperativo da globalização. A educação passou por transformações profundas, nas suas funções e organização, na 
tentativa de se adequar às demandas a elas apresentadas; demandas que provocaram maios sobrecarga de trabalho docente e, logicamente, maior adoecimento.

A educação passou a ser fundamentada nos conceitos de produtividade, eficácia, excelência e eficiência, importando categorias e valores econômicos para o setor educacional. As mudanças provocaram, em parte, reestruturação do trabalho docente, com maior responsabilização dos professores pelos fracassos escolares. Os professores são considerados os principais responsáveis pelo desempenho dos alunos, da escola, do sistema de educação. As exigências exacerbadas contribuem para um sentimento de perda de identidade profissional, na medida em que os professores se sentem obrigados a responder às novas exigências pedagógicas e administrativas.

Sampaio e Marin (2004), ao realizarem densa discussão sobre a precarização do trabalho escolar e seus efeitos nas práticas curriculares, ressaltam alguns pontos importantes que nos ajudam a compreender a precarização docente no Brasil dado que corrobora nossa pesquisa. As autoras destacam que a feminização do magistério ocorre paralelamente à precarização docente. Em 1990 havia 1,5 milhão de homens e 3,6 milhões de mulheres exercendo o magistério. Em 1997 já havia 1,8 milhão de homens e 4,2 milhões de mulheres. Esse dado é interessante, pois corrobora a hipótese de que as mulheres se encontram socialmente mais expostas ao regime social de trabalho, que é opressivo, competitivo e individualista. A demanda por se tornar uma trabalhadora competente e qualificada ultrapassa as condições físicas e psíquicas dessas mulheres. Nesse sentido, o trabalho gradativamente perde seu caráter produtor de identidade pessoal e coletiva, tornando-se produtor de adoecimento e sofrimento. $\mathrm{Na}$ China, Kang et al. (2009) constataram que as professoras tem mais dor corporal, menos vitalidades e saúde do que os seus pares do gênero masculino. A tensão psicológica e física, a sobrecarga de trabalho e o estresse profissional agravam as condições de saúde física e mental das mulheres.

Uma das questões apontadas por Sampaio e Marin (2004) é a precarização do trabalho docente em relação aos salários. O Brasil só oferece salários mais elevados que a Indonésia e se encontra entre os sete piores países do mundo em termos de remuneração docente. Dados de 1997 informam-nos que a média salarial docente na educação básica brasileira era de $\mathrm{R}$ \$ 529,92, alcançando valores de R\$ 221,22 na Paraíba, por exemplo. Não podemos deixar de mencionar que a 
pauperização profissional implica pauperização da vida pessoal nas suas relações entre vida e trabalho. Além do salário, a precarização docente está relacionada às condições de trabalho, como carga horária excessiva, tamanho das turmas e rotatividade. Ao recorrer aos dados do Instituto Nacional de Estudos e Pesquisas Educacionais (INEP), do Ministério da Educação, Sampaio e Marin (2004) revelam que o número médio de alunos por turma é de 37,6 no Brasil, podendo chegar a 43,0 em Sergipe. Um professor chega a ter 600 alunos no total de sua carga horária semanal. Enquanto em países europeus e anglo-saxões há 14 a 17 alunos por professor, no Brasil há 28,9-38,4.

Diante desse número excessivo de alunos, a sobrecarga de trabalho se torna insuportável e as relações humanas e cordiais entre professores e alunos se perdem. Toda relação inspiradora e transferencial de amor entre docentes e discentes vai se perdendo na medida em que o professor é lançado na tarefa de gerir uma sala de aula com 50 alunos. Daí multiplicam-se os casos de LER, DORT, doenças nas cordas vocais, hipertensão arterial, tendinites, gastrites e, obviamente, fibromialgia.

Já precisei obter licença médica do trabalho, sim. A recuperação está sendo retardada devido à fibromialgia. Eu era alfabetizadora com carga horária de 40 horas semanais, com 30 alunos em cada turma, trabalhando em escolas distantes. As cobranças eram muitas. Principalmente por causa das minhas constantes faltas e elas vinham dos pais e da direção da escola. Se eu acho que meu trabalho contribuiu para a doença? Com certeza. Só de pensar em voltar para a sala de aula entro em pânico. Desenvolvi a síndrome do pânico paralelo a fibromialgia (41 anos, casada, professora).

Eu era professora de ensino fundamental. Meu trabalho era muito estressante porque dava aula com média de 35 alunos por sala. Era uma cobrança enorme. Tanto as crianças, quanto os pais e até mesmo a direção achavam que era frescura minha essas dores todas no meu corpo. Ninguém aceitava. Tive que ficar de licença médica, mas os peritos da prefeitura não acreditam que uma pessoa tão nova como eu possa ter uma doença tão complexa (26 anos, solteira, professora).

A docência, se não gera, impulsiona as dores generalizadas pelo corpo. $\mathrm{O}$ malestar se somatiza, provocando marcas sensoriais no corpo feminino, oriundas de marcas culturais. Mais do que nunca, percebe-se a relação íntima entre adoecimento e cultura. Trata-se de uma relação semelhante - porém não igual à descrita por Freud entre o mal-estar na civilização e as psicopatologias. 


\section{Considerações finais}

Constatamos empiricamente, através de estudo de caso, o adoecimento das mulheres com fibromialgia como fruto da perda de sentidos para o trabalhar e o viver. Nossa hipótese central é que esta perda é fruto direto da organização e do regime social de trabalho atual a que são submetidas essas mulheres. A lógica do trabalho na sociedade capitalista atual vem contribuindo sensivelmente para a perda de sentidos e de identidades no trabalho, gerando com isto um processo de sofrimento e adoecimento progressivo (LUZ, 2006; 2007; 2008). Quando estabelecemos a relação entre adoecimento, sofrimento e fibromialgia, é preciso ficar claro que não estamos defendendo um nexo causal. Há um paradigma determinista que supõe a causalidade como explicação universal de ligação entre os fenômenos e define o universo como um conjunto finito de leis a serem descobertas e descritas em linguagem formal preferencialmente matemática. Não é esse paradigma que fundamenta nossa pesquisa. $\mathrm{O}$ conteúdo sócio-histórico, cultural e político das relações é vital para a compreensão do objeto de estudo.

Interpretamos a própria atividade de trabalho como geradora de sofrimento, ao invés de realização pessoal e coletiva, e a partir desta constatação discutimos a existência possível de estratégias para contornar este processo. Que estratégias são essas? Percebemos, no presente estudo e em estudos anteriores (MATTOS; LUZ, 2009), que as próprias práticas corporais coletivas (BOURDIEU, 1984; 1997), quando portadoras de valores e sentidos solidários, podem ser uma das estratégias sociais que contribuem para a diminuição da sensação de sofrimento e opressão no trabalho.

É importante ressaltar que Marx considera ao trabalho alienado não somente como externo ao trabalhador e alheio a sua natureza, mas também como gerador de sofrimento em vez de bem-estar, pois não desenvolve livremente suas energias mentais e físicas. Pelo contrário, torna o trabalhador fisicamente exausto e mentalmente deprimido. O trabalhador, portanto, só se sente à vontade em seu tempo de folga, enquanto no trabalho se sente contrafeito. Seu trabalho não é voluntário, porém imposto, é trabalho forçado. Surgem a hostilidade e a insatisfação frente ao trabalho, que provocam insatisfação para com a própria existência. 
A hipótese interpretativa do estudo, de caráter sociológico, é que as representações sociais sobre o trabalho e o trabalhar no regime de produção social capitalista contemporâneo contribuem para a geração de sofrimento dos sujeitos - levando à somatização, inclusive na forma de dor -, aumentando o número de diagnósticos de fibromialgia. Em 2009, fizemos um levantamento entre mulheres e $64 \%$ alegaram ter nível de estresse elevado ou muito elevado no trabalho; 75,5\% alegaram que frequentemente ou sempre têm dores agravadas pelo trabalho e $52 \%$ afirmam que já precisaram de licença médica pelo menos uma vez em razão do adoecimento.

A impossibilidade de responder à demanda do tipo ideal de "trabalhador produtivo" no regime de trabalho atual gera sintomas manifestados corporalmente na forma de dor. Do nosso ponto de vista, cabe às ciências sociais no campo da Saúde Coletiva interpretar os aspectos sociais e culturais que fazem surgir ou mantêm morbidades coletivas, ou tendência a certos tipos de adoecimento individual e coletivo.

$\mathrm{Na}$ década de 1970, a crise do capitalismo revelou o esgotamento do modelo fordista de produção e do regime social de trabalho estabelecido até então. Uma nova maneira de organizar a produção e o regime social de trabalho foi implementada nos países capitalistas centrais e estendida aos países periféricos (atualmente de países "em desenvolvimento" ou "emergentes"). Foi a chamada Reestruturação Produtiva, cujo objetivo era aumentar a produtividade sem aumentar os custos da produção, em especial, sem aumentar a mão de obra empregada (o que gerou sobrecarga de trabalhado para cada trabalhador).

O mundo pós-moderno, ao rejeitar as grandes narrativas da cultura ocidental como a dialética do Espírito, a hermenêutica do sentido, a emancipação do sujeito racional, o privilégio da razão instrumental, a crença na ciência como transformadora da realidade e democratizadora de bens e serviços, a confiança nas instituições democráticas e no mercado como promotores do bem-estar coletivo, entre outras, modificou também os modos e relações de produção (FOURNIER, 2001; LYOTARD, 1984).

Novas formas de organização do trabalho têm substituído o fordismo; a imensa e complexa classe média substituiu a clássica e rígida divisão de classes sociais. Há uma descontrução dos discursos marxistas sobre a relação entre capital 
e trabalho, ao mesmo tempo em que as contradições dessa relação se tornam mais

evidentes. A produção industrial como força de trabalho produtora diminuiu sua importância, enquanto o capital se tornou supervalorizado como motor da produção - vide o crescimento do sistema financeiro e suas crises na Europa e nos Estados Unidos. O risco e as divididas do capital privado são assumidos pelos Estados Nacionais e, por efeito, pelos trabalhadores.

Tornou-se comum o corte de trabalhadores sem que houvesse diminuição na produtividade, sobretudo em razão da incorporação de tecnologias, como a informatização e as telecomunicações. A jornada de trabalho foi ampliada, acompanhada de imensa campanha para que o trabalhador "vestisse a camisa" da empresa. O uso crescente da informática e da automatização dos postos de trabalho não conseguiu eliminar as doenças relacionadas ao trabalho. Patologias, mesmo sem agente etiológico específico, continuaram a surgir, como os transtornos psíquicos associados ao trabalho, burn out, entre outros. As síndromes músculo-esqueléticas fazem parte deste novo momento e, em especial, destacamos a fibromialgia, além dos inúmeros trabalhos existentes sobre LER e DORT (GOMES, 2003).

Em levantamento preliminar realizado em junho de 2008, no projeto de extensão Tratamento Interdisciplinar para Portadores de Fibromialgia da UERJ, constatamos que $47 \%$ das mulheres alegam que o nível de estresse no trabalho é elevado ou muito elevado, e $22 \%$ estão de licença médica do trabalho por causa da dor. Outros estudos constataram que 58\% das mulheres que adoeceram, em 2003, em função do trabalho possuíam dores músculo-esqueléticas (JEANNEAU, 2008; QUÉRUEL, 2008).

Trata-se, portanto, de compreender o novo regime social de trabalho que impôs mudanças no ritmo e intensificou as atividades laborais. $\mathrm{O}$ bom trabalhador deve ser aquele disponível a se deslocar a qualquer momento a pedido da empresa, abrindo mão de seus desejos e interesses pessoais e familiares. Com isso, aumenta-se a perda da identidade profissional e o trabalho deixa de ser compreendido como meio de expressão de sentidos para a vida. Assim, cada vez mais constatamos a existência de sofrimento relacionado à pressão no trabalho, falta de reconhecimento e desconhecimento acerca da importância daquilo que se faz, falta de perspectiva de crescimento profissional ${ }^{2}$. 


\section{Referências}

AIACH, P.; KAUFMANN, A.E.; WAISSMAN, R. Vivre une maladie grave: analyse d'une situation de crise. Paris: Méridiens Klincksieck, 1989.

AMERICAN PSYCHIATRIC ASSOCIATION. Diagnostic and statistical manual of mental disorders. 4th ed. Washington, DC: APA, 1994.

AUQUIER, L. et al. La fibromyalgie. La Revue de Médecine Interne, v. 29, n. 2, p. 161-168, 2008. BERBER, J.S.S.; KUPEK, E.; BERBER, S.C. Prevalência de depressão e sua relação com a qualidade de vida em pacientes com síndrome da fibromialgia. Revista Brasileira de Reumatologia, São Paulo, v. 45, n. 2, p. 47-54, mar./abr. 2005.

BOURDIEU, P. Questions de sociologie. Paris: Minuit, 1984. . Méditations pascaliennes. Paris: Seuil, 1997.

CASTEL, R. Les métamorphoses de la question sociale: une chronique du salariat. Paris: Fayard, 1995. (Col. Léspace politique).

CATHEBRAS, P.; LAUWERS, A.; ROUSSET, H. La Fibromyalgie: une revue critique. Annales de Médicine Interne. Paris, v. 149, n. 7, p. 406-414, 1998.

CAVALCANTE, A.B. et al. A prevalência de fibromialgia: uma revisão de literatura. Revista Brasileira de Reumatologia. São Paulo, v. 46, n. 1, p. 40-48, jan./fev. 2006.

DEJOURS, C. Travail, usure mentale: essai de psychopathologie du travail. Paris: Bayard Jeunesse, 2008.

DEJOURS, C. (Dir.). Observations cliniques en psychopathologie du travail. Paris: PUF, 2010. 224 p. (Collection Souffrance et théorie).

DESRIAUX, A. Troubles musculo-squelettiques: à quand une prévention durable? Santé \& Travail, n. 62, avril 2008.

DURAND, C. Le Travail Enchaîne: organization du travail et domination sociale. Paris: Seuil, 1978.

DURET, P.; ROUSSEL, P. Le corps et ses sociologies. Paris: Nathan, 2003.

DURKHEIM, E. O que é o Fato Social? In: RODRIGUES, J.A. (Org.). Émile Durkheim: Sociologia. 9 ed. São Paulo: Ática, 2004 (Coleção Grandes Cientistas Sociais).

EL-HAGE, W. et al. V. Fibromyalgie: une maladie du traumatisme psychique? La Presse Medicale, Paris, v. 35, n. 11, p. 1683-1689, 2006.

FOURNIER, M. Postmodernité: Une idée fin de siècle? Sciences Humaines, n. 30 (100 ans de sciences humaines), janvier/février 2001.

FOUCAULT, M. Naissance de la clinique. Paris: PUF, 2003.

FOUCAULT, M. Résumé des cours (1970-1982). Paris: Julliard, 1989. 
GOMES, I. A contribuição da racionalidade médica na construção do diagnóstico: LER, doença ou imaginação? Dissertação (Mestrado em Saúde Coletiva) - Instituto de Medicina Social, Universidade do Estado do Rio de Janeiro, Rio de Janeiro, 2003.

GROOPMAN, J. Hurting All Over: With so many people in so much pain, how could fibromyalgia not be a disease? The New Yorker, 13 nov. 2000.

HERZLICH, C.; PIERRET, J.P. Malades d'hier, malades d'aujourd'hui. Paris: Bibliothèque Scientifique Payot, 1991.

JEANNEAU, L. Maladies professionnelles: les femmes plus exposées. Alternatives Economiques, n. 272, set. 2008.

KANG, X. et al. Relationship between quality of life and occupational stress among teachers. Public Health, v. 123, n. 11, p. 750-755, nov. 2009.

KOKOREFF, M.; RODRIGUEZ, J. Une société de l'incertitude. Sciences Humaines, n. 50, sept.-oct. 2005.

LE BRETON, D. Anthropologie de La Douleur. Paris: Métailié, 1995.

LYOTARD, J-F. The Postmodern Condition: a report on knowledge. Minneapolis: University of Minnesota Press, 1984.

LUZ, M.T. Natural, Racional, Social: razão médica e racionalidade científica moderna. 2. ed. rev. São Paulo: Hucitec, 2004.

LUZ, M.T. Cultura Contemporânea e Medicinas Alternativas: Novos Paradigmas em Saúde no Fim do Século XX. PHYSIS: Revista de Saúde Coletiva. Rio de Janeiro, v. 15 (supl.), p. 145-176, 2005a.

LUZ, M. Novos Saberes e Práticas em Saúde Coletiva: estudo sobre racionalidades médicas e atividades corporais. 2. ed. rev. São Paulo: Hucitec, 2005b.

LUZ, M. Fragilidade social e busca de cuidado na sociedade civil de hoje. In: PINHEIRO, R.; MATTOS, R.A. (Org.). Cuidado: as fronteiras da integralidade. 3 ed. Rio de Janeiro: Cepesc, 2006.

Perda da ética no trabalho acadêmico: geração de sofrimento e doença entre trabalhadores universitários a partir do produtivismo como valor-fim entre pesquisadores docentes. In: PINHEIRO, R.; MATTOS, R.A. (Org.). Razóes Públicas para a integralidade em saúde: o cuidado como valor. Rio de Janeiro: Cepesc, 2007.

Notas sobre a política de produtividade em pesquisa no Brasil: Consequências para a vida acadêmica, a ética no trabalho e a saúde dos trabalhadores. Política \& Sociedade: Revista de Sociologia Política. Florianópolis, v. 7, n. 13, p. 205-228, out. 2008.

MARQUES, A.P. et al. Pain Evaluation of patients with fibromyalgia, osteoarthritis, and low back pain. Revista do Hospital de Clínicas., São Paulo, v. 56, n. 1, p. 5-10, jan./fev. 2001. 
MARX, K. Manuscritos Econômico-Filosóficos. São Paulo: Boitempo, 2004.

. O Capital. 3 ed. São Paulo: Edipro, 2008.

MATTOS, R.S.; LUZ, M.T. Sobrevivendo ao Estigma da Gordura: um estudo socioantropológico sobre Obesidade. Physis: Revista de Saúde Coletiva, v. 19, n. 2, p. 489507, 2009.

MAUSS, M. A expressão obrigatória dos sentimentos (rituais orais funerários australianos). In: Ensaios de Sociologia. 2 ed. São Paulo: Perspectiva, 2005 (Col. Estudos, 47). p. 325-335.

MAUSS, M. Ensaio sobre a dádiva: forma e razão da troca nas sociedades arcaicas. In: . Sociologia e Antropologia. V. II. São Paulo: Pedagógica e Universitária, 1974.

MOULIN, A.M. O corpo diante da medicina. In: COURTINE, J.-J. (Dir.). História do Corpo. V. III (As mutações do olhar - O século XX). Petrópolis: Vozes, 2008.

OLIVEIRA, D.A. A reestruturação do trabalho docente: precarização e flexibilização. Educação \& Sociedade. Campinas, v. 25, n. 89, p. 1127-1144, set./dez. 2004.

QUÉRUEL, N. Quand le travail malmène les femmes. Paris, juil. 2008.

RESNIK, D.B.; REHM, M. The undertreatment of pain: scientific, clinical, cultural, and philosophical factors. Medicine, Health Care and Philosophy, v. 4, n. 3, oct. 2001.

ROQUELAURE, Y. Des pathologies parfois très invalidantes. Santé \& Travail, n. 62, avril 2008 (Troubles musculo-squelettiques: à quand une prévention durable?).

ROSENBERG, C. Contested Boundaries: psychiatry, disease, and diagnosis. Perspectives in Biology and Medicine, v. 49, n. 3, p. 407-424, 2006.

SÁ, E. et al. A dor e o sofrimento: algumas reflexões a propósito da compreensão psicológica da fibromialgia. Revista Portuguesa Psicossomática, Porto, v. 7, n. 1-2, p. 101-113, 2005.

SAMPAIO, M.M.F.; MARIN, A.J. Precarização do Trabalho Docente e seus Efeitos sobre as Práticas Curriculares. Educação \& Sociedade. Campinas, v. 25, n. 89, p. 1203-1225, set./ dez. 2004.

SANTOS, A.M.B. et al. Depressão e Qualidade de Vida em Pacientes com Fibromialgia. Revista Brasileira de Fisioterapia. São Carlos, v. 10, n. 3, p. 317-324, jul./set. 2006.

SOCIEDADE BRASILEIRA DE REUMATOLOGIA. Consenso e Diretrizes de Fibromialgia, São Paulo: SBR, 2004.

SORDET-GUEPET, H. L'insaisissable fibromyalgie. L'Évolution Psychiatrique, v. 69, n. 4, p. 671-689, 2004.

SYNNOTT, A. The body social: simbolism, self and society. London: Routledge, 1993. 
TESSER, C.D. A verdade na biomedicina, reações adversas e efeitos colaterais: uma reflexão introdutória. PHYSIS: Revista de Saúde Coletiva. Rio de Janeiro, v. 17, n. 3, p. 465-484, 2007. TESSER, C.D.; LUZ, M.T. Racionalidades médicas e integralidade. Ciência \& Saúde Coletiva. Rio de Janeiro, v. 13, n. 1, p. 195-206, 2008.

WEBER, M. L'éthique protestante et l'esprit du capitalisme. Paris: Gallimard, 2004.

\section{NotaS}

${ }^{1} \mathrm{O}$ projeto é coordenado pelo Laboratório de Fisiologia aplicada à Educação Física (LAFISAEF), localizado na Rua São Francisco Xavier no 524 - $8^{\circ}$ andar - Bloco F - Sala 8.104. Tel: (21) 2234-0107 ou 2234-0553. Está registrado na Sub-Reitoria de Extensão e atende a mais de cem pacientes por ano. A pesquisa foi submetida e aprovada pelo Comitê de Ética do Instituto de Medicina Social da UERJ.

${ }^{2}$ R. Mattos foi responsável pela discussão teórico-conceitual e metodológica do artigo, coleta dos dados, análise dos mesmos e discussão. M. Luz participou da discussão dos resultados e fez a revisão teórica para a redação final. 


\section{Abstract}

\section{When the loss of meaning in the world of work involves pain and suffering: a case study on fibromyalgia}

Fibromyalgia is a rheumatic syndrome that affects many women in the Brazilian population. There is the current hypothesis that the social labor regime has contributed to increased rates of fibromyalgia, resulting in illness and collective suffering. The unease generated is somatized as chronic pain, anxiety and depression, symptoms typical of fibromyalgia. This paper is a product of ethnographic research with more than 60 women diagnosed with fibromyalgia. The loss of positive directions in relation to work and disenchantment with work activity involves pain and suffering. Fibromyalgia has become, along with RSI and WRMD cases, an effect of the restructuring of capital-labor ratio in recent decades.

Key words: Fibromyalgia; capitalism; illness; labor regime. 